\title{
Desain Produk Kerajinan dan Ornamen Bangunan Bergaya Etnik Dayak dari Hasil Pengolahan Injeksi Limbah Plastik
}

\author{
Suwarto dan Rusda \\ Politeknik Negeri Samarinda \\ Jl. Dr.Cipto Mangun Kusumo Gn Lipan Samarinda \\ Email : suwartopoltek78@gmail.com
}

\begin{abstract}
The increase of plastic use in Indonesia in general and in Kalimantan in particular will also increase the amount of plastic waste that will be produced. By using plastic waste heater device which driven by 3 tones hydraulic, be able to produce fine quality of handcraft and building ornament product, this can be seen in the test result of device so that the recycling process can take place. By heating at the temperature of $270^{\circ}-280^{\circ} \mathrm{C}$ on bengkirai wood mold combined with iron plate, plastic bag ( HDPE), household wastes can be molded into Dayak's motif which then can be used for ornament building. Processed injection plastic modul which then can be arranged into ornament building. To be used as the building ornament the modules of plastic injection are glued on the wooden frame which itended to facilitate when combined as ornament of building.
\end{abstract}

Key Words: Plastic, Heater, Mold, Modules, Dayak.

\begin{abstract}
ABSTRAK
Dengan meningkatnya penggunaan plastik di Indonesia umumnya dan Kalimantan pada khususnya maka akan meningkatkan juga jumlah limbah plastik yang akan dihasilkan. Dengan menggunakan alat pemanas limbah plastik yang digerakkan dengan hydraulic berkapasitas 3 (tiga) ton mampu menghasilkan produk kerajinan dan ornament bangunan yang berkualitas baik, ini terlihat pada hasil uji alat sehingga proses recycle dapat berlangsung. Dengan pemanasan pada mesin pencetak menggunakan suhu $270^{\circ}-280^{\circ}$ pada cetakan kayu bengkirai kombinasi plat besi, plastik kresek (HDPE) limbah rumah tangga dapat dicetak menjadi modul bermotif Dayak yang selanjutnya dapat digunakan untuk ornamen bangunan. Dihasilkan modul plastik injeksi yang kemudian dapat dirangkai menjadi ornamen bangunan. Untuk dapat digunakan sebagai ornamen bangunan modul-modul hasil injeksi plastik tadi di rekatkan pada bingkai kayu dimaksudkan agar memudahkan pada saat di gabungkan sebagai ornamen bangunan.
\end{abstract}

Kata kunci : Plastik, Pemanas, Cetakan, modul, Dayak 


\section{PENDAHULUAN}

Limbah plastik saat ini menjadi salah satu isu penting dunia karena jumlahnya yang semakin banyak sementara bahaya yang ditimbulkan dapat merusak kelestarian lingkungan hidup. Karena alasan tersebut maka banyak sekali usaha yang dilakukan baik untuk mengurangi penggunaannya, penggunaan kembali maupun mendaur ulang limbah plastik atau dikenal dengan istilah 3R (Reduce, Reuse, Recycle). Pemerintah Daerah Kalimantan Timur juga mendukung program pemerintah untuk turut serta berperan dalam upaya penanganan perubahan iklim dengan mendeklarasikan program "Kaltim Hijau" dalam bentuk rencana aksi dimana salah satu sektornya adalah lingkungan hidup dan salah satu programnya adalah pengelolaan sampah. Hal ini juga sesuai dengan UU 18/ 2008 tentang Pengelolaan Sampah melalui pengurangan di sumber (reduce at source) dan daur ulang sumberdaya (resources recycle).

Sampah plastik jenisnya bermacammacam, menurut Pratiwi (2006) dalam penelitiannya menjelaskan pemilahan sampah dikategorikan menjadi 7 (tujuh) macam, yaitu Burnable Waste, Plastic Waste, Landfill Waste, Recyclable Waste, Hazardous Waste, Bulky Waste, dan Crushable Waste. Untuk sampah plastik yang dapat didaur ulang terdiri dari plastik PET, LDPE, HDPE, PVC, PP, PS dan Multilayer atau pada produk yang terdapat tanda tiga anak panah melingkar. Untuk melelehkan plastik, menurut Kadir dalam penelitiannya menyatakan bahwa kantong kresek 500 gram dibutuhkan waktu 930 detik dengan temperatur nyala api 300p C, botol 500gram waktu yang dibutuhkan 1515 detik dengan temperatur nyala api 415 p C sedangkan botol aqua 500 gram dibutuhkan waktu 1221 detik dengan temperatur nyala api 400p C.
Metode pengolahan sampah atau limbah plastik menjadi produk yang mempunyai nilai jual ada berbagai cara mulai dari yang paling sederhana sampai penggunaan mesin. Menurut Suharto (2009) dalam penelitiannya menyatakan bahwa pemanfaatan limbah plastik dapat dilakukan dengan penggunaan kembali (re-use) dengan mempertimbangkan kesehatan dan dengan cara daur ulang untuk dibentuk menjadi produk baru (re-cycle) seperti dudukan kaki meja, kaki almari, aksesoris rangka baja, segita pengaman lalu lintas dan masih banyak lagi yang lain. Produk baru dari daur ulang plastik yang mempunyai pasar tinggi, volume kecil, konstrusi sederhana sehingga mudah dibentuk cetakan/mold serta memenuhi persyaratan lesehatan.

Penelitian pengolahan limbah plastik yang dilakukan oleh Willy (2010), dilakukan dengan memotong rantai produksi sampah plastik-gilingan-flakes-pasta-bijih plastik/ pellet sebelum dicacah menjadi bijih plastik/ pellet sehingga pasta dicetak melalui extrusion molding menjadi untaian plastik dengan diameter $\pm 3 \mathrm{~mm}$ yang siap dianyam. Pemrosesan material termoplastik dilakukan dengan melelehkan material melalui pemanasan yang diinjeksikan oleh screw ke dalam setakan dies yang kemudian didinginkan oleh air dimana material tersebut akan menjadi dingin dan mengeras ketika ditarik oleh puller dengan profil nozzle bervariasi seperti pada penampang pada bahan-bahan helai anyaman rotan, yang lazim disebut dengan lasio/peel, pitrit dan juga jenis profil lainnya, sehingga dapat dihasilkan berbagai tipe helai anyaman seperti pada bambu ataupun rotan.

Pada penelitian Suwarto (2013) merancang mesin injeksi plastic untuk kapasitas industri rumah tangga. Hasilnya adalah mesin yang memiliki volume barrel (tabung) 15 cc, konsumsi daya 280 watt, 


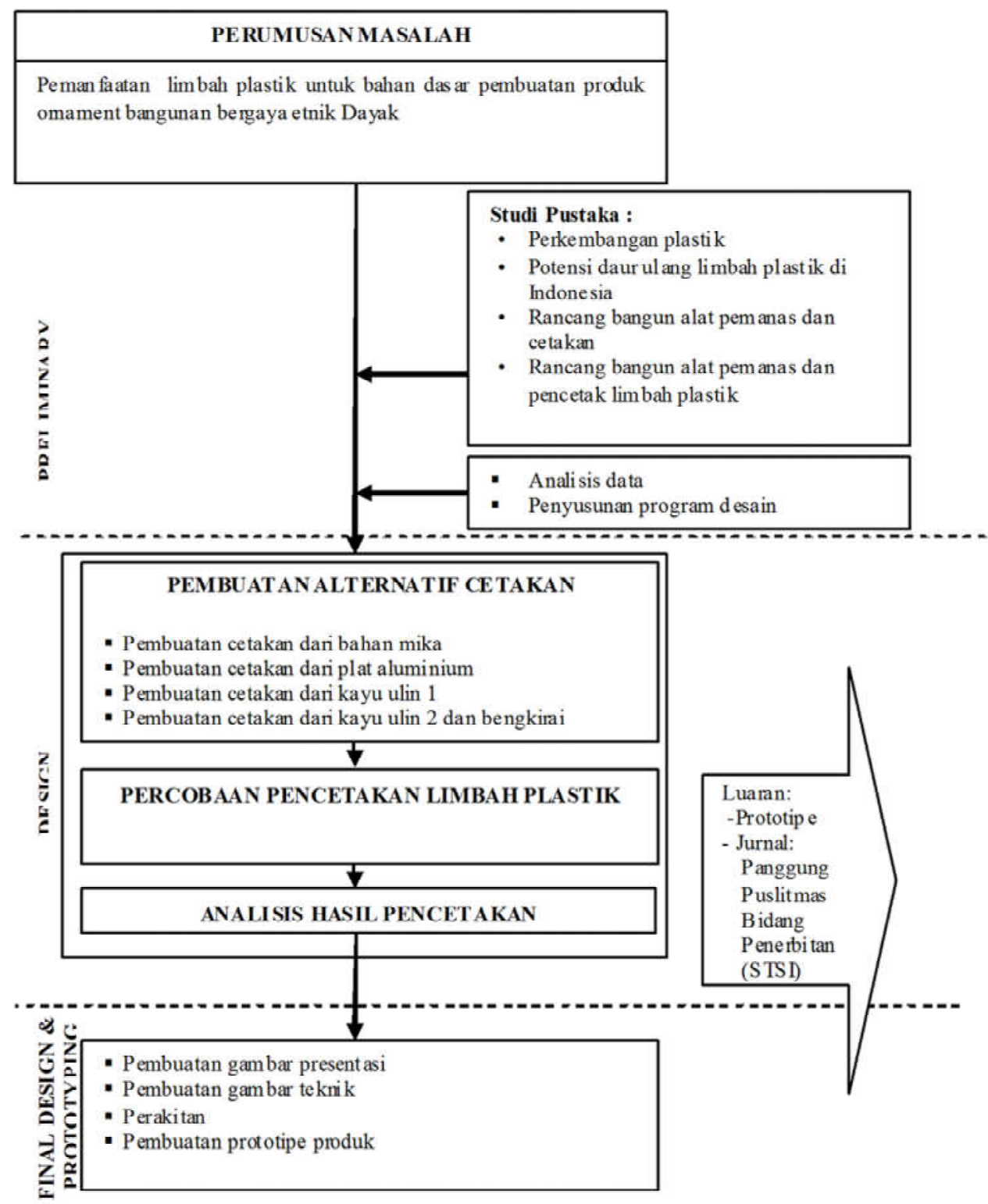

Gambar 1.

Diagram metodologi penelitian

dan sistem penekanan manual. Mesin ini berukuran $80 \mathrm{~cm} \times 40 \mathrm{~cm} \times 180 \mathrm{~cm}$ dengan berat $50 \mathrm{~kg}$. Sistem pemanas mesin ini mampu memanaskan plastik hingga temperatur $320^{\circ} \mathrm{C}$ dan waktu yang diperlukan untuk pemanasan awal mesin ini adalah 6 menit, sedangkan waktu jeda antara satu injeksi dengan injeksi berikutnya kurang lebih 2 menit.

Penelitian ini adalah kelanjutan dari penelitian Suwarto (2013) sebelumnya yakni fokus pada aplikasi produk olahan dari plastik yang dipanaskan. Produk yang dihasilkan ini nantinya akan di aplikasikan pada ornamen bangunan.

\section{METODE}

Proses pengembangan desain dapat menggunakan tehapan-tahapan proses desain,menurut Lawson (1990), beberapa tahapan pelaksanaan yang harus dilakukan secara terus menerus sebagai berikut : 


\section{A. Preliminary Design}

Pengumpulan data dan informasi, analisis data berdasarkan konsep desain makro yang meliputi analisis (konsep fungsi, konsep pemakai, konsep pasar dan konsep produk), penyusunan program desain dan sketsa awal.

\section{B. Design Developmnet}

Pembuatan alternatif model kasar dengan skala $1: 5$ atau $1: 1$, pembuatan alternatif gambar teknik, pembuatan alternatif konsep desain, solusi desain, detail desain produk (struktur konstruksi, pemilihan bahan baku \& proses pembentukan) serta desain ornamen (motif).

\section{Final Design E Prototyping}

Pembuatan gambar presentasi, pembuatan gambar teknik (gambar tampak, gambar potongan, gambar detail dan spesifikasi teknis produk), assembling (exploded), prototyping, packaging design dan uji pasar.

Tahapan di atas dapat dijelaskan dengan diagram (Gambar 1.1):

\section{Studi Pustaka}

\subsection{Landasan Teori}

Jenis-Jenis Mesin Plastik Molding

Berdasarkan Material Plastik yang digunakannya Plastic Molding dapat dibedakan atas beberapa jenis, yaitu: (Hartomo, 1993)

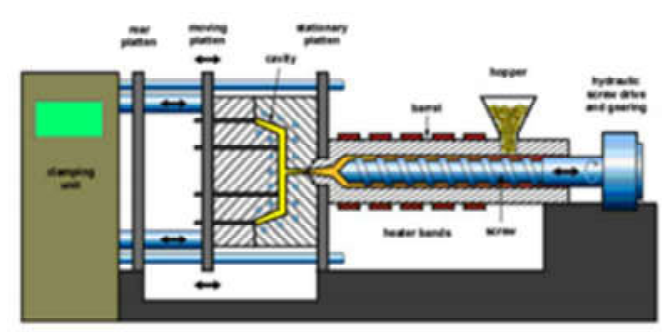

Gambar 2

Unit Mesin Injcetion Moulding (Hartomo, 1993)

\section{HASIL DAN PEMBAHASAN \\ Injection Molding}

Proses injection molding merupakan proses yang sering digunakan dalam industry manufaktur plastic. Termoplastik dalam bentuk butiran atau bubuk ditampung dalam sebuah hopper kemudian turun ke dalam barrel secara otomatis (karena gaya gravitasi) dimana ia dilelehkan oleh pemanas yang terdapat di dinding barrel dan oleh gesekan akibat perputaran sekrup injeksi. Plastik yang sudah meleleh diinjeksikan oleh sekrup injeksi (yang juga berfungsi sebagai plunger) melalui nozzle ke dalam cetakan yang didinginkan oleh air. Produk yang sudah dingin dan mengeras dikeluarkan dari cetakan oleh pendorong hidrolik yang tertanam dalam rumah cetakan selanjutnya diambil oleh manusia atau menggunakan robot.
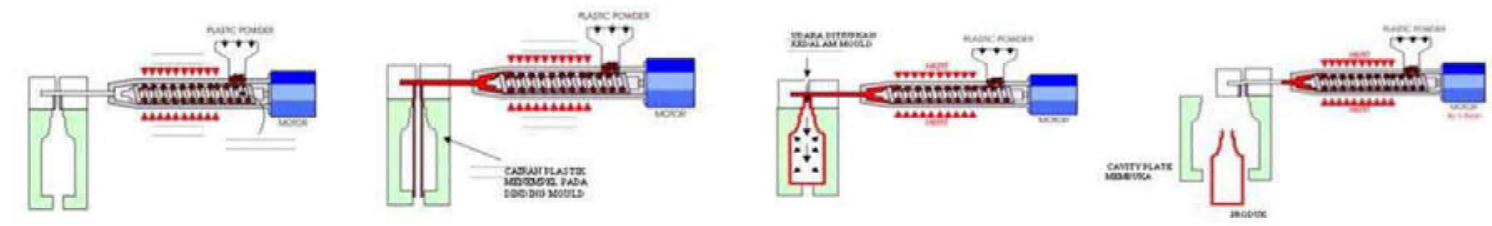

Gambar 3.

Proses pengisian, pemanasan, peniuoan dan pengeluaran produk 


\section{Blowing molding}

Blow molding merupakan suatu metode mencetak benda kerja berongga dengan cara meniupkan atau menghembuskan udara kedalam material/bahan yang menggunakan cetakan yang terdiri dari dua belahan mold yang tidak menggunakan inti (core) sebagai pembentuk rongga tersebut.

\section{Compression molding}

Compression molding (thermoforming) merupakan metode mold plastic dimana material plastik (compound plastic) diletakan ke dalam mold yang dipanaskan kemudian setelah material tersebut menjadi lunak dan bersifat plastis, maka bagian atas dari die atau mould akan bergerak turun menekan material menjadi bentuk yang diinginkan. Apabila panas dan tekanan yang ada diteruskan, maka akan menghasilkan reaksi kimia yang bisa mengeraskan material thermoplastik tersebut.

\section{Extrusion molding}

Extrusion molding suatu proses pembentukan plastic secara continue yang menggunakan mesin ektruder dan material yang akan dibentuk akan berupa bentukan profil tertentu yang panjang, seperti pipa, batang, lembaran, film, filament, pelapis kabel listrik, dan lainnya.

\section{Rotational molding}

Mencakup pemanasan dan pemutaran bahan thermoplastic dalam cetakan tertutup sekitar dua sumbu yang saling tegak. Putaran itu membagikan muatan bahan plastiknya ke dinding dalam cetakan, yang masing-masing kemudian mengalami pendinginan.

\section{Calendering}

Calendering adalah cara membuat film atau lembaran plastic dengan menekannya lewat celah/sela atau nip antara dua silinder yang berputar lawan arah.
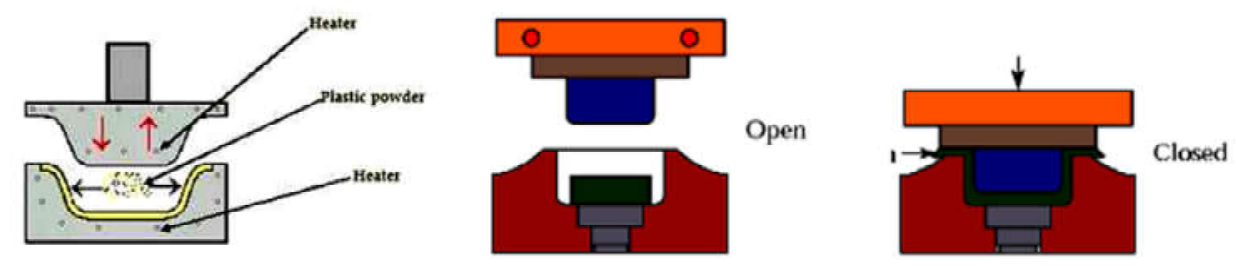

Gambar 4.

Metode Compression Molding (Hartomo, 1993)

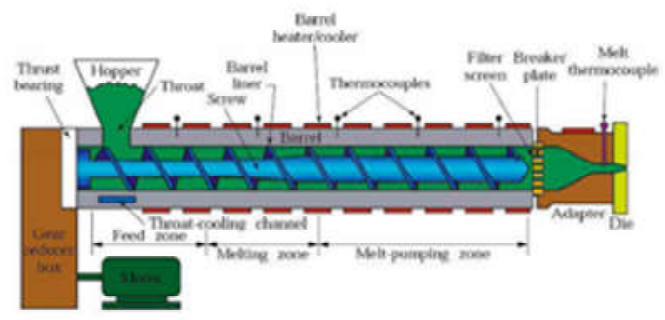

Gambar 5

Metode Extrusion Molding (Hartomo, 1993)

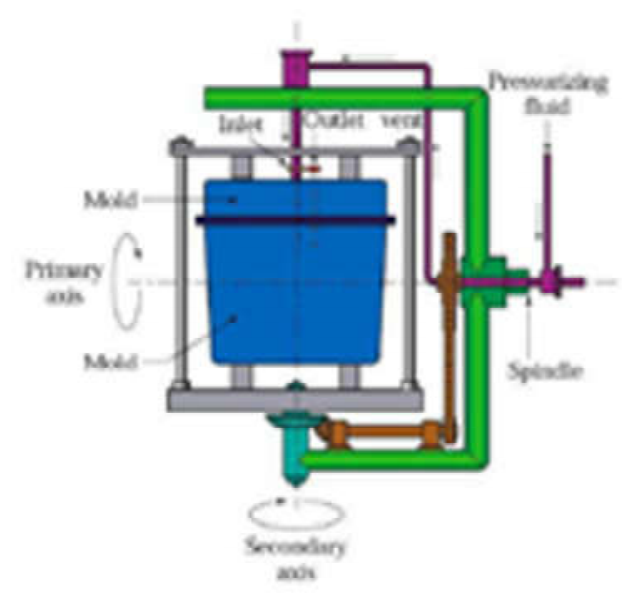

Gambar 6.

Metode Rotational Molding (Hartomo, 1993) 


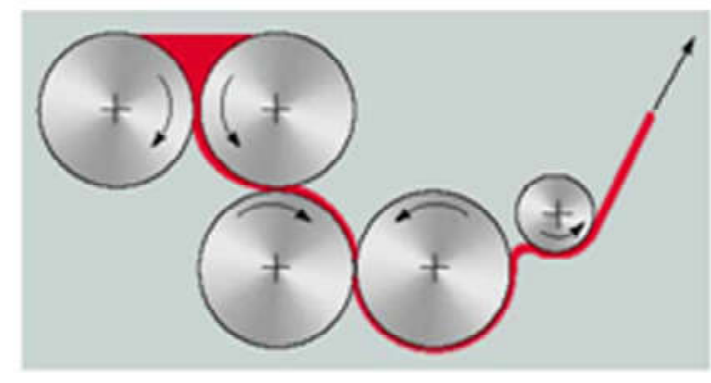

Gambar 7.

Metode Calendering (Hartomo, 1993)

Potensi Daur Ulang Limbah Plastik di Indonesia

Potensi limbah plastik sangat besar jika dilihat dari jumlahnya yang menduduki peringkat kedua setelah sampah dapur. Sudah banyak dilakukan usaha yang mencakup 3R (re-duce, re-use dan re-cycle) terhadap limbah plastik yang ada. Namun dari beberapa penelitian yang telah dilakukan menyatakan bahwa masih banyak peluang untuk mengolah limbah plastik.

Penelitian yang dilakukan oleh Oswari (2006) tentang potensi nilai ekonomis pengelolaan sampah di Kota Depok berasumsi bahwa sampah memberikan nilai ekonomis, baik sampah organik yang dapat didaur ulang maupun sampah anorganik yang tidak dapat didaur ulang. Dilihat dari jumlah sampah yang dihasilkan dengan asumsi semua sampah dapat dimanfaatkan baik untuk daur ulang ataupun yang anorganik, dan dengan perkiraan residu 5\% dari total sampah serta perkiraan jumlah keluarga, nilai ekonomis sampah tahun 2020, pendapatan daerah akan bertambah sebesar 187.951.800 setiap hari jika sampah dikelola dengan baik.

Menurut Sidarto (2010) dalam penelitian analisis usaha proses pengelolaan sampah rumah tangga dengan pendekatan cost and benefit ratio guna menunjang kebersihan lingkungan menyatakan bahwa dengan menggunakan profitablility index, dimana present value net cash flow sebesar Rp. 19.001.900,- dan present value initial outlays sebesar Rp. 17.955.600,- maka hasil dari PI sebesar 1,05 atau lebih besar dari satu, maka usaha proses pengelolaan sampah rumah tangga dapat diterima. Selain mendapatkan keuntungan, membuka usaha proses pengelolaan sampah rumah tangga juga akan membantu meningkatkan kebersihan lingkungan.

Menurut Sharadvita (2012) dalam penelitiannya yang berjudul Potensi dan Alur Perjalanan Material Daur Ulang Sampah di Unit Pengolahan Sampah Kampung Sasak, Limo, Depok didapatkan kesimpulan potensi daur ulang sampah ditunjukkan dengan recycling rate dan nilai ekonomi. Potensi recycling rate sebesar $83,18 \%$ dan recycling rate eksisting yang didapatkan di lapangan adalah 25,65\%. Sedangkan nilai ekonomi sampah setiap harinya sebesar Rp. 551.179,-, di mana nilai ekonomi sampah organik adalah Rp. 183.990,- dan sampah anorganik adalah Rp. $367.189,-$.

\section{Analisis}

Penelitian ini diawali dengan melakukan percobaan menggunakan berbagai material cetakan, yakni cetakan mika, alumunium, dan kayu ulin sampai pada cetakan kayu bengkirai kombinasi dengan plat besi. Cetakan dimaksudkan untuk membuat modul-modul cetakan plastik yang nantinya akan dirangkai menjadi produk ornamen bangunan. Plastik yang digunakan adalah plastik limbah kresek (HDPE) dari rumah tangga. Berikut hasil dari berbagai percobaan yang dilakukan :

\section{Proses Penginjeksian Plastik \\ - Cetakan Mika}

Pada percobaan menggunakan cetakan mika, mika dibuat dengan desain umum 


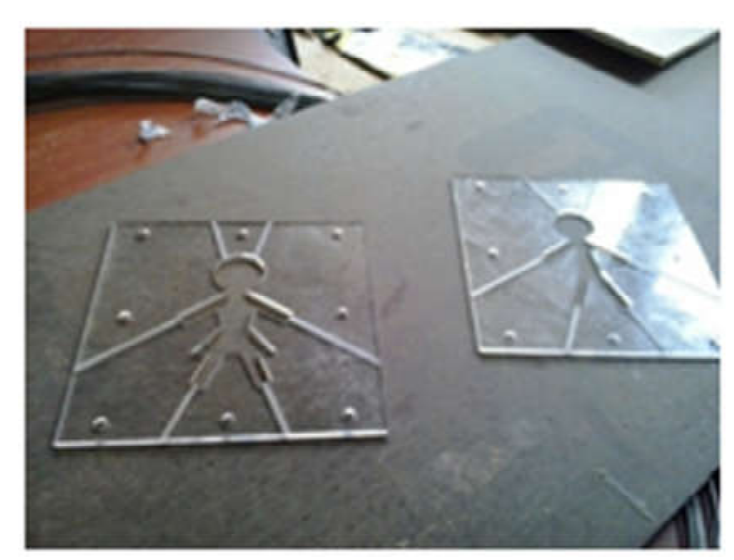

Gambar 8.

Cetakan mika ( Doc. Pribadi 8 Juli 2014)

(bukan motif Dayak). Cetakan dibuat 3 (tiga) lapis mika. Lapisan pertama dan ketiga merupakan penutup, sedang lapisan kedua merupakan cetakan yang berbentuk motif. Penyatuan ketiga mika menggunakan skrup dan baut untuk mengunci dan merapatkan ketiga lapisan mika agar cairan tidak meluber ke samping. Selain proses pembuatan cetakan dari mika yang agak rumit jika dibentuk motif Dayak (harus menggunakan mesin (NC), hasil yang dicapai pun kurang maksimal. Dengan ketebalan cetakan sekitar $2 \mathrm{~mm}$, dan di-inject plastik pada suhu $\pm 270-280^{\circ} \mathrm{C}$, cetakan mudah retak dan patah. Mika dengan ketebalan $2 \mathrm{~mm}$ tidak tahan dengan panas $\pm 270-280^{\circ} \mathrm{C}$. Proses penginjeksian diawali dengan mengatur cetakan pada mesin dan suhu disesuaikan kemudian dilanjutkan pengisian plastik injeksi pada cetakan.

\section{- Cetakan Alumunium}

Cetakan ini dibuat seperti halnya dengan cetakan mika, yakni tiga lapis dengan cetakan bermotif pada lapisan kedua. Pada cetakan alumunium ini pun agak rumit dan susah jika dibentuk menjadi motif dayak. Jika ingin sempurna bentuk motif Dayak-nya harus menggunakan mesin CNC. Cetakan yang berhasil dibuat dalam penelitian ini adalah sebanyak 3 cetakan. Seperti hal sebelumnya proses penginjeksian diawali dengan mengatur cetakan pada mesin dan suhu disesuaikan kemudian dilanjutkan pengisian plastik injeksi pada cetakan. Alumunium mampu menghantarkan panas, tapi dalam salah satu percobaan yang dilakukan cetakan motif alumunium (pada sulur motif Dayak) patah ketika diinject plastik bersuhu $\pm 270-280^{\circ}$ C. Kekurangan pada cetakan ini terletak pada tingkat kesukaran dalam melepas hasil plastik injeksian di cetakan. Berikut gambar hasil percobaan dengan menggunakan cetakan alumunium.
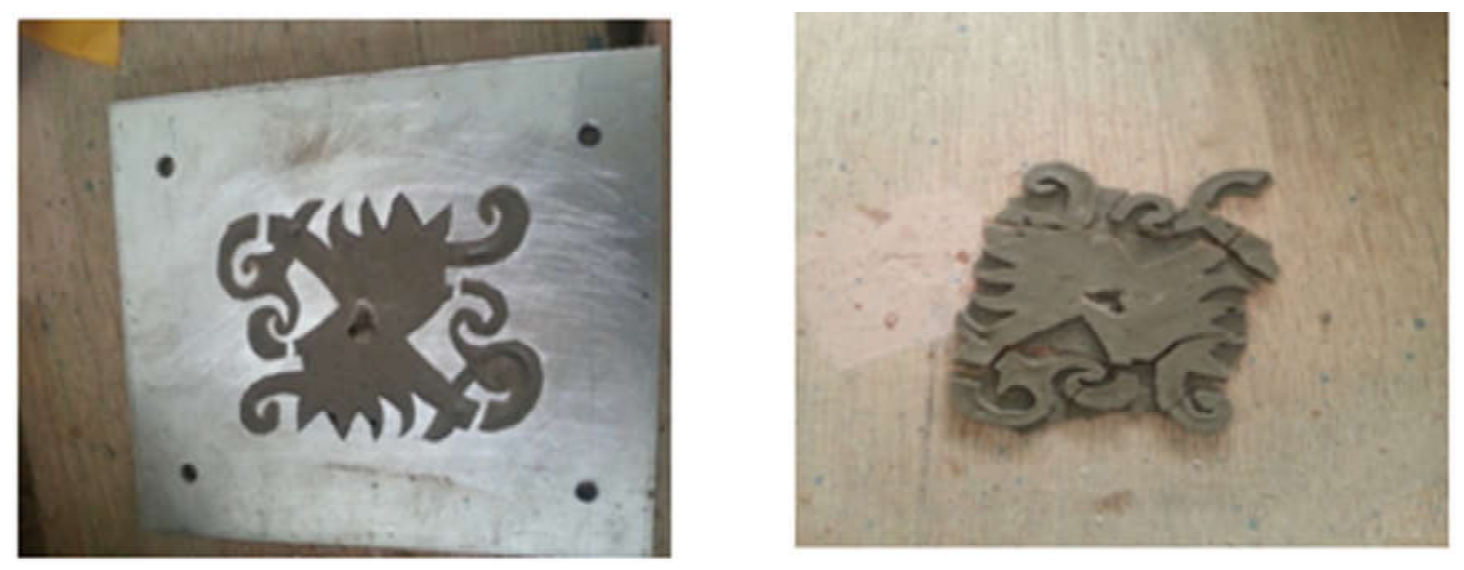

Gambar 9.

Hasil penginjeksian menggunakan cetakan alumunium mika

( Doc. Pribadi 10 Juli 2014) 

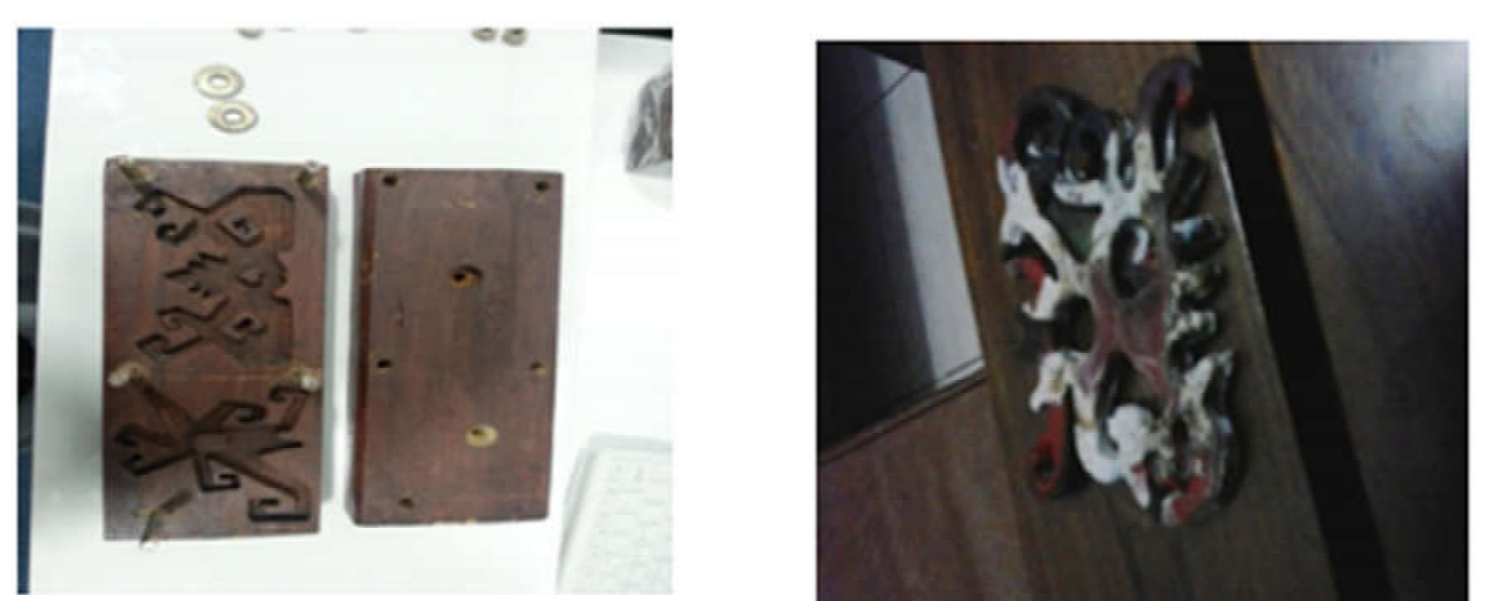

Gambar 10.

Hasil akhir injeksi plastik dengan cetakan kayu ulin versi I ( Doc. Pribadi 8 Juli 2014)

\section{- Cetakan Kayu Ulin Versi I}

Didasari dengan kegagalan dengan kedua cetakan sebelumnya, maka dibuat cetakan motif dayak dari kayu. Walaupun kayu bukan penghantar panas yang baik tetapi salah satu alasannya digunakan kayu sebagai media cetak dikarenakan oleh tingkat kemudahan kayu untuk diukir menjadi motif dayak.

Cetakan kayu ulin versi I dibuat dalam bentuk blok motif dua lapisan. Lapisan pertama merupakan cetakan negatif yang di ukir motif dayak dan lapisan kedua merupakan tutup cetakan yang ditujukan agar hasil injeksi tepat masuk dan berbentuk sesuai cetakan negatif. Kedua lapisan tadi direkatkan dengan menggunakan skrup dan baut. Berikut gambar cetakan (Gambar 2.3).

Pada percobaan dengan menggunakan cetakan kayu versi I ternyata menghasilan modul bermotif dayak. Cetakan kayu ulin berhasil membentuk modul motif dan nantinya modul-modul tadi dapat dirangkai menjadi ornamen bangunan. Namun modul yang dihasilkan sukar untuk di rangkai walaupun sebelum penginjeksian plastik cetakan telah diberi pelumas, sehingga dibutuhkan pengembangan bentuk cetakan motif Dayak sehingga hasil cetakan mudah di keluarkan dari cetakan negatif, dan mudah dirangkai modul per modul. Berikut hasil percobaan injeksi plastik menggunakan cetakan kayu ulin versi I (Gambar 2.3).

Sebelum proses pemanasan dan penginjeksian plastik pada cetakan, sebelumnya cetakan di lumuri pelumas agar mudah dalam proses pengeluaran dari cetakan. Lalu plastik dimasukkan dan dipanaskan hingga suhu $\pm 270-290^{\circ} \mathrm{C}$. Suhu $\pm 270-290^{\circ} \mathrm{C}$ adalah suhu yang ideal bagi limbah plastik meleleh dan bisa mempertahankan warnanya. Waktu yang dibutuhkan untuk menginjeksi plastik ke dalam cetakan adalah 30 menit. Plastik yang dibutuhkan untuk menginjeksi tepat sesuai cetakan adalah $+/-6$ kantong plastik ukuran $2,5 \mathrm{~kg}$ (200 cc).

\section{- Cetakan kayu ulin versi II}

Cetakan kayu ulin versi II ini dibuat dengan pengembangan desain motif pada cetakan. Desain motif ini di ubah dengan pemberian dasar pada motif dengan harapan hasil injeksian dapat dikeluarkan dengan mudah (Gambar 2.4). Cetakan keseluruhan terbuat dari kayu ulin, terdiri 


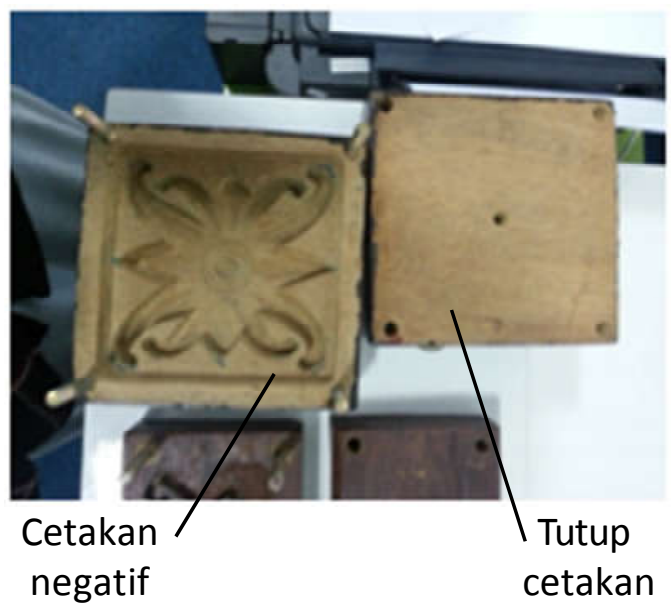

Gambar 11.

Cetakan kayu ulin versi I (Doc. Pribadi 19 Juli 2014)

dari dua lapisan yakni lapis pertama sebagai cetakan negatif dan lapis kedua sebagai tutup. Proses penginjeksian sama seperti pada cetakan kayu ulin versi I. Pada cetakan ini plastik tidak berhasil terinjeksi sempurna karena plastik tidak dapat terdistribusi semourna ke seluruh cetakan dan lapisan tutup retak oleh panas langsung injeksian plastik dalam jangka waktu yang lebih lama dari cetakan ulin versi I. Jangka waktu penginjeksian plastik lebih lama daripada cetakan versi I karena volume cetakan lebih luas $(10 \mathrm{~cm} \times 10 \mathrm{~cm} \times 1,6 \mathrm{~cm})$ dan plastik yang digunakan pun lebih banyak ( 18 kantong kresek ukuran 2,5 kg, +/- 200 cc)

- Cetakan Ulin kombinasi tutup plat besi Melihat kegagalan percobaan sebelumnya maka dilakukan kembali pengembangan cetakan, yakni pada bagian tutup dibuat dari bahan plat besi yang tahan panas dan merupakan penghantar panas yang baik, sedangkan cetakan negatifnya masih terbuat dari ulin (Gambar 2.6).

Kapasitas cetakan, derajat panas dan kapasitas plastik yang akan diijeksi sama seperti pada cetakan sebelumnya. Waktu yang digunakan dalam peoses penginjeksian pada plastik adalah +/- 50 menit. Pada

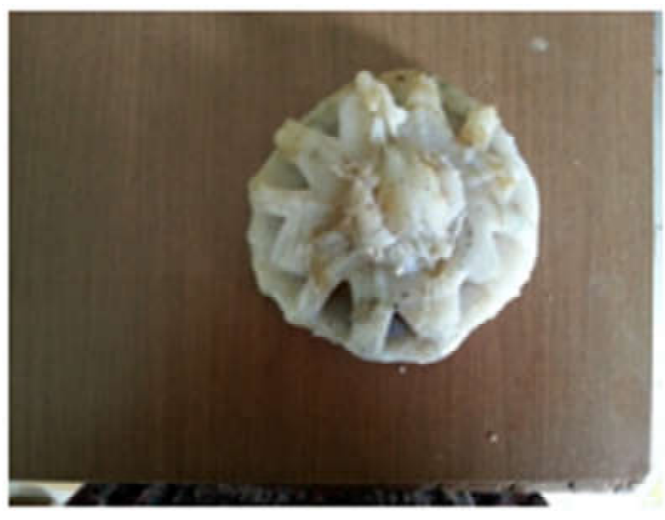

Gambar 12.

Hasil Injeksi plastik

(Doc. Pribadi 19 Juli 2014)

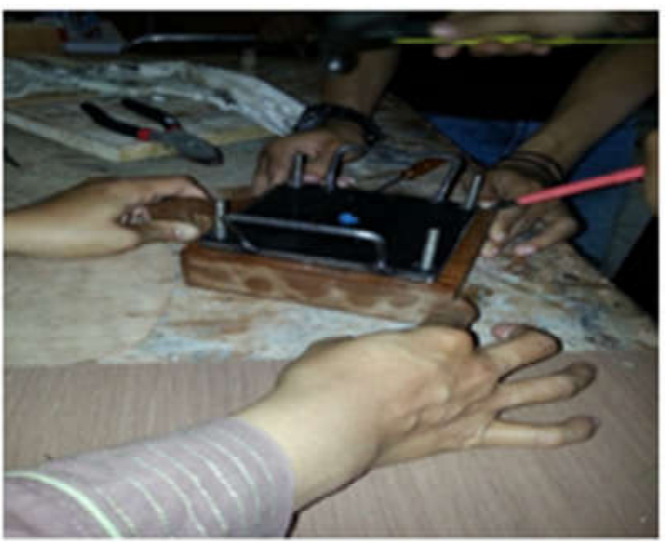

Gambar 13.

Cetakan kayu kombinasi tutup plat besi ( Doc. Pribadi 26 Juli 2014)

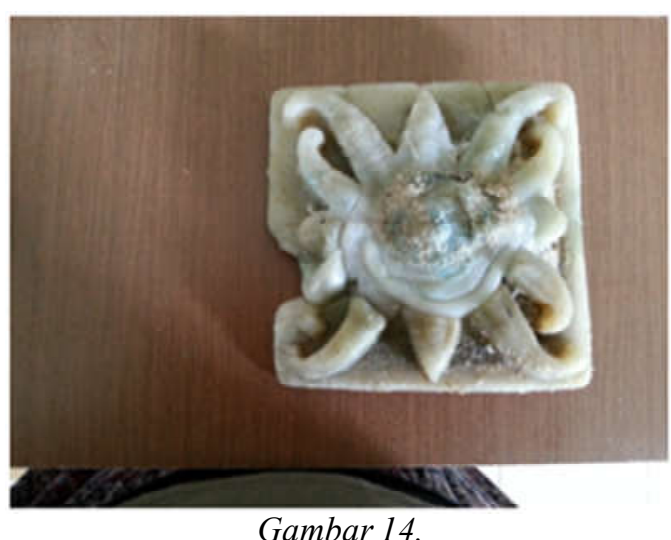

Hasil injeksi plastik dengan Cetakan kayu ulin kombinasi tutup plat besi ( Doc. Pribadi 26 Juli 2014) 
percobaan menggunakan cetakan ini ternyata plastik berhasil terinjeksi sempurna ke seluruh permukaan cetakan (Gambar 2.7), namun kegagalan terjadi pada cetakan negatif yang retak karena tidak tahan terhadap tekanan panas dalam jangka waktu lama yang di berikan saat penginjeksian. Hal tersebut karena sifat kayu ulin yang memiliki tingkat keretakan tinggi.

\section{- Cetakan Kayu Bengkirai Kombinasi Tutup Plat Besi}

Dari keberhasilan dan kegagalan percobaan sebelumnya maka dilakukan kembali pengembangan cetakan, yakni pada lapiasan negatif cetakan terbuat dari kayu bengkirai dengan pertimbangan kayu ini mudah diukir dan lebih tahan dari retak

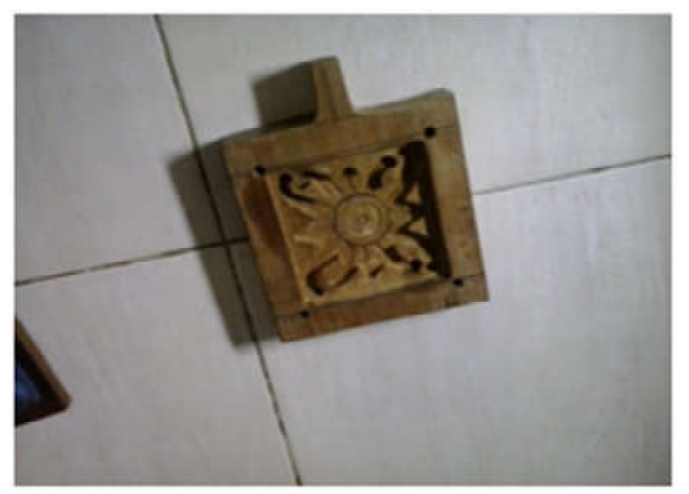

akibat pemanasan dan tekanan, sedangkan lapisan tutup cetakan tetap terbuat dari plat besi dengan pertimbangan lebih tahan panas dan merupakan penghantar panas yang baik (Gambar 2.8).

Kapasitas cetakan, derajat panas dan kapasitas plastik yang akan diijeksi sama seperti pada cetakan sebelumnya. Pada percobaan menggunakan cetakan ini ternyata plastik berhasil terinjeksi sempurna ke seluruh permukaan cetakan tanpa adanya cacat pada cetakan. Hasil dari penginjeksian plastik dengan menggunakan cetakan kayu bengkirai terlihat pada gambar 2.9.

\section{Proses Aplikasi Hasil Injeksi Pada Ornamen Bangunan}

Setelah dilakukan penginjeksian plas-

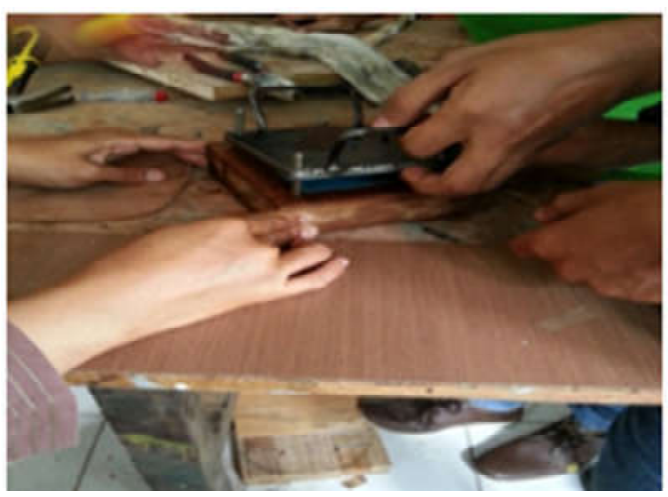

Gambar 15.

Cetakan kayu bengkirai kombinasi tutup plat besi (Doc. Pribadi 10 Agustus 2014)
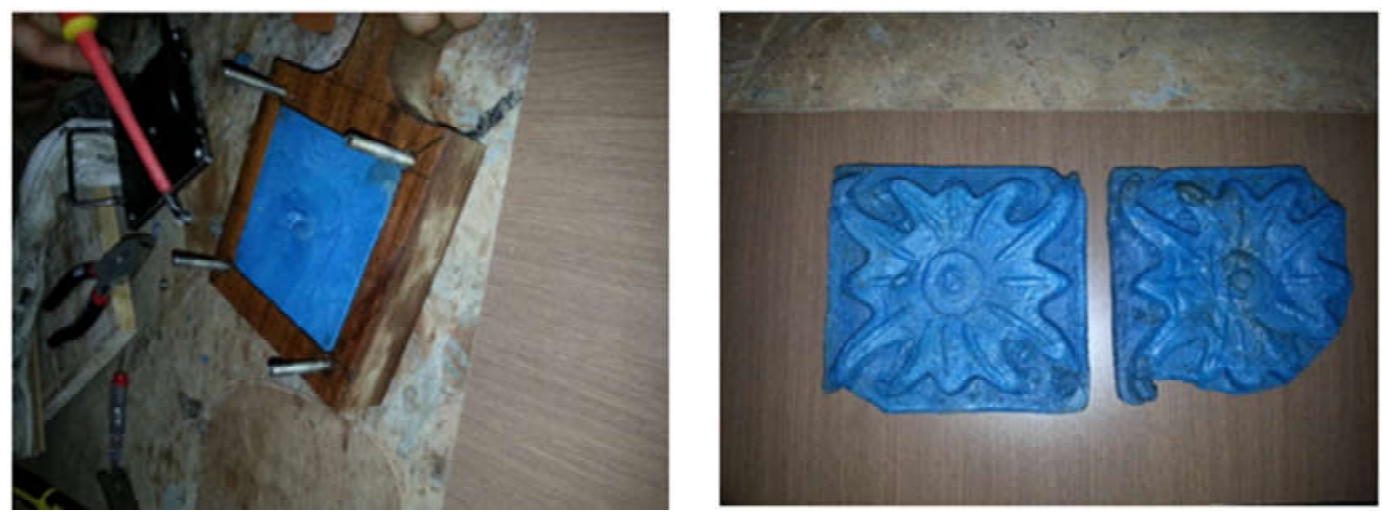

Gambar 16.

Hasil injeksi plastik dengan cetakan kayu bengkirai

kombinasi tutup plat besi

( Doc. Pribadi 10 Agustus 2014) 


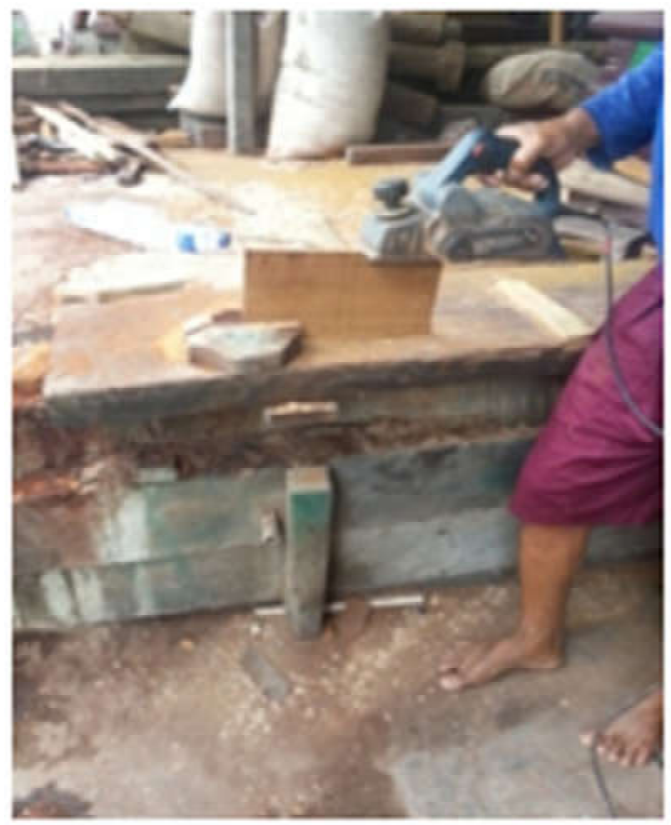

Gambar 17.

Proses mengamplas/meratakan kayu (Doc. Pribadi 22 Agustus 2014)

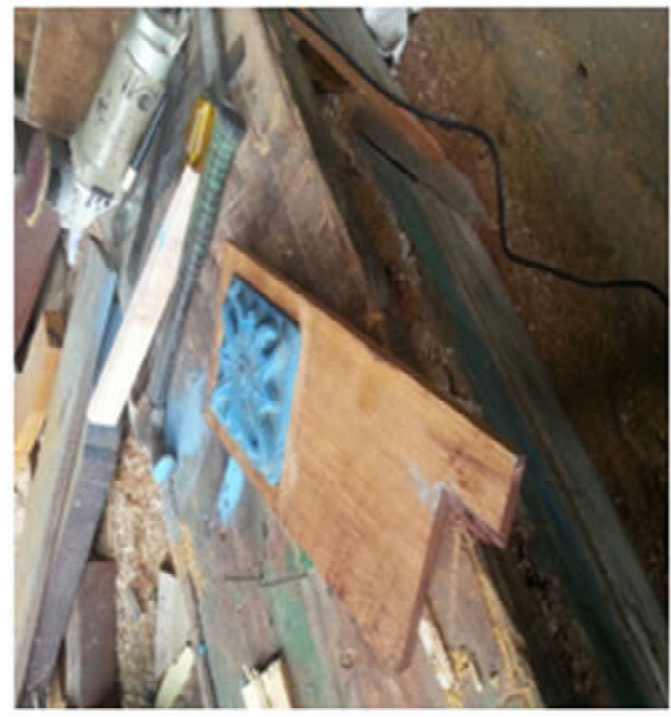

Gambar 19.

Proses pencetakan hasil injeksi (Doc. Pribadi 22 Agustus 2014)

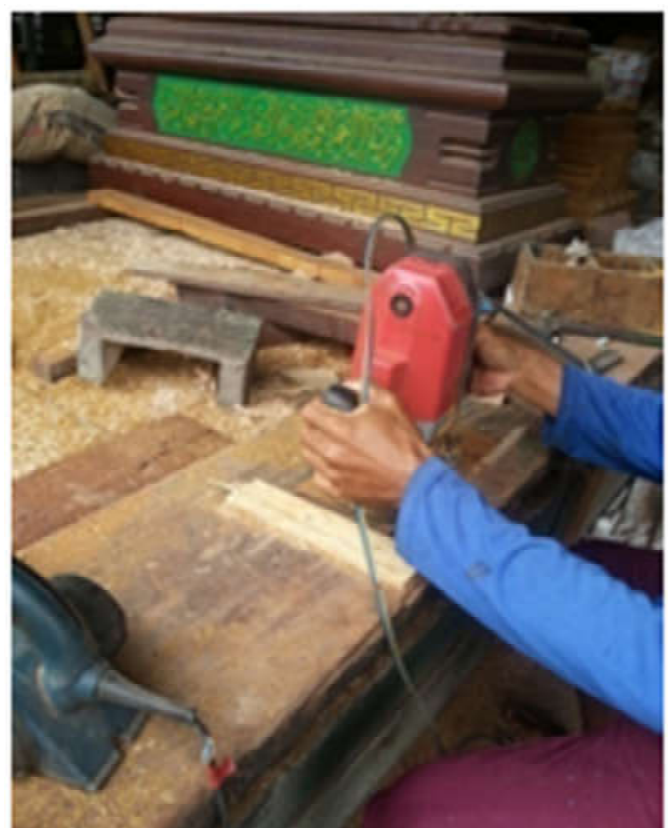

Gambar 18.

Proses pelubangan kayu sebagai cetakan (Doc. Pribadi 22 Agustus 2014)

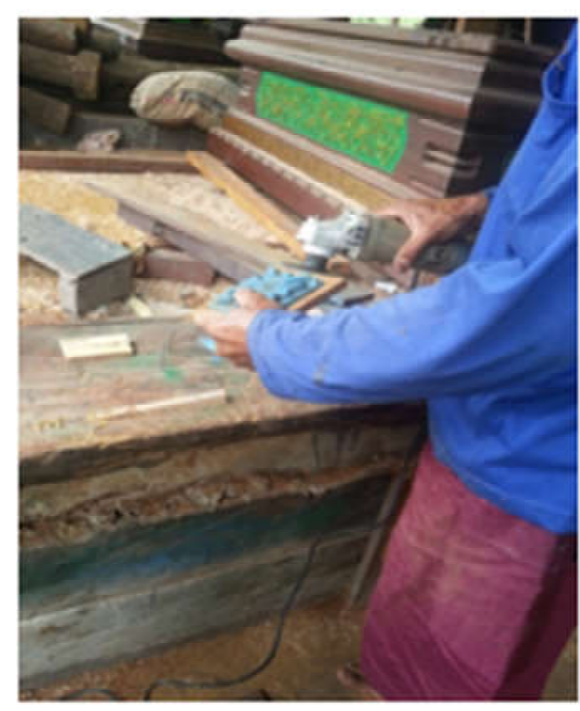

Gambar 20.

Proses penghalusan cetakan modul (Doc. Pribadi 22 Agustus 2014) tik, maka tahap selanjutnya adalah proses pengaplikasian hasil injeksi pada ornamen bangunan. Tekstur yang tidak rata pada bagian belakang hasil injeksi plastik menyebabkan agak sukar untuk di rangkai tiap modulnya. Sebagai solusinya maka di buatlah bingkai dari kayu ulin yang mendasari dari modul injeksian plastik. Proses tahapan pembingkaian modul seperti pada gambar 2.10 -2.13. Hasil injeksi plastik diletakkan di tengah bingkai kemudian di sekrup bagian tengahnya agar hasil injeksi plasik tidak terlepas.

Modul-modul (Gambar 2.14) tadi pada ornamen bangunan dapt diaplikasikan pada berbagai macam ornamen bangunan. 
Pemakaiannya yaitu di tanamkan dan dirangkai pada lapisan semen sebagai pengikat pada bangunan (Gambar 2.152.18).

\section{SIMPULAN}

1. Proses peleburan plastik masih manual.

2. Jenis cetakan yang dapat menghasilkan modul dengan bentuk yang sempurna dan cetakan tidak cacat akibat tempaan plastik panas yang keluar dari tabung adalah bentuk blok dimana cetakan negatifnya terbuat dari kayu bengkirai dan tutupnya terbuat plat besi.

3. Modul hasil injeksi plastik harus di beri dasaran berupa bingkai kayu ulin agar modul mudah di rangkai pada ornamen bangunan dan terlihat lebih estetis.

\section{Daftar Pustaka}

Arif

2012 "Perancangan dan Pembuatan Alat Injeksi Plastik Manual untuk Kapasitas Limbah Plastik Rumah Tangga". Laporan Tugas Akhir, Univrsitas Islam Indonesia: Yogyakarta.
Deny Willy.

2010 Desain Produk Kerajinan Daur Ulang Sampah Plastik dengan Cetak Injeksi. Yayasan Apikayu: PT. Ganesa Plastik

Dwi Siwi Handayani

2009 "Kajian Nilai Ekonomi Penerapan Konsep Daur Ulang pada TPA Jatibarang Kota Semarang".Jurnal PRESIPITASI. Vol.7 No.2.

Hartomo Anton

1993 Penuntun Analisis Polimer Aktual. Andi Offset. Yogyakarta.

Kadir.

2012 "Kajian Pemanfaatan Sampah Plastik sebagai Sumber Bahan Bakar Cair". Jurnal Ilmiah Teknik Mesin DINAMIKA Vol.3,No.2, Mei 2012

Nugrah

2007 "Studi Pemanfaatan Nilai Ekonomi Sampah Anorganik melalui Konsep Daur Ulang dalam Rangka Optimalisasi Pengelolaan Sampah (Studi Kasus : Kota Magelang)". Jurnal TEKNIK-Vol.28 No.1.

Suharto

2009 "Rancangan Produk Bahan Plastik Daur Ulang sebagai Upaya Peningkatan Industri Kreatif" 